\title{
Accuracy of Regeneration Stocking Estimates: Tests with Simulated Data
}

\section{MacLeod}

Forest Productivity Program

Forest Management Institute

Ottawa, Ontario

\begin{abstract}
A computer was used to generate points representing tree seedlings in an area of natural regeneration. These seedlings were than sampled and the per cent stocking calculated for $2 \mathrm{~m} \times 2 \mathrm{~m}$ (milacre) plots. A systematic survey design was used, employing a wide variety of plot spacings. Groups of plots were included as well as single plots. For each spacing, repeated surveys were run and a standard error was estimated for the stocking level. Graphs were drawn to show the approximate sampling intensity required to estimate stocking to a given accuracy, for 10-ha and 40-ha sample areas.
\end{abstract}

\section{Résumé}

L'auteur utilisa un ordinateur pour créer des points représentant des populations de semis dans un terrain à reboiser. Puis il échantillonna ces semis, et le pourcentage de densité, dans des placettes de $2 \mathrm{~m}$ sur $2 \mathrm{~m}$, fut calculé. II utilisa plusieurs méthodes de relevé et fit varier de beaucoup la distance d'une placette à l'autre. II inclut des groupes de placettes, outre des placettes seules. Pour chaque design, il effectua plusieurs relevés et il estima l'erreur type de niveau de densité. II traça des graphiques pour montrer l'intensité approximative des échantillonnages nécessaire pour estimer la densité à un niveau de précision donné dans des aires d'échantillonnage de 10 ha et 40 ha.

\section{Introduction}

The assessment of forest regeneration usually makes use of the stocked plot or "quadrat" concept. In this approach a plot containing one or more seedlings is stocked, a plot with none is unstocked. Much has been written concerning various mathematical aspects of stocked-plot or stocked-quadrat sampling for regeneration. Most of these have dealt with such problems as the effect of quadrat size on stocking levels (Grant 1951, Cottam et al. 1953) or the dependence of stocking levels on seedling density (Gill 1950, Wellner 1940). Although a few authors have considered the question of how accurate such stocking figures are, e.g. Clark (1972), they have dealt only with particular cases, and with seedlings assumed to be randomly located.

\section{The Problem of Estimating Accuracy}

It is difficult to get even a rough estimate of the accuracy of the per cent stocking figure produced by any given survey, because of the large number of factors that contribute to the results. Ghent (1963) discusses many of these in connection with the sampling of numbers of seedlings per quadrat. Some factors are a consequence of the sample design employed in the survey, such as the size of the quadrats, the spacing of the quadrats and the size of the regeneration area sampled.

Certain properties of the seedling population being sampled also affect the accuracy of the stocking estimate. For example, if stocking levels are about $50 \%$, estimates are generally less accurate than when levels are either close to $0 \%$ or close to $100 \%$. This 'rule' holds because there is much less 'room' for sample variation at the high or low ends of the scale. These effects are somewhat difficult to deal with statistically. Some investigators such as Persson (1974) hold that seedling populations have only two properties that need to be taken into account - average density, and 'distribution' or degree of clustering. The same view is taken in this paper, except that a third property - cluster size - was also considered. Stocking accuracy was related to these properties. The degree of clustering was estimated by the variance-to-mean ratio for the number of seedlings per milacre plot.

Finally there is the question of inaccuracy due to mistakes of the sampling crew. The magnitude of this factor is difficult to assess, since it depends on the particular crew, the field conditions, the amount of sampling time allotted per plot and so on. Any attempt to deal with these variables would seem to require testing under field conditions, something beyond the scope of this report. It should be noted, though, that Ghent (1963) found significant bias (values too large) in tests concerning the sampling of numbers of seedlings per plot. This was found even with well-trained observers under good field conditions.

\section{The Use of Computer-Generated Seedling Populations}

Reasons for Using Artificial Data: The statistically rigorous way to estimate the accuracy ${ }^{1}$ of a particular stocking value would be to repeat the survey many times on the same area, using the same sample design with a different randomly chosen starting point each time. Probably at least twenty such repetitions would be needed to get a reasonable estimate - clearly not a practical procedure.

The situation would be much simpler if a general formula could be found that applies to all sur- 
veys. Such a formula could be derived if it were assumed that all seedling populations follow some exact mathematical distribution. The known statistical properties of the distribution could then be used to estimate the stocking accuracy for certain survey designs. The only workable population for this purpose appears to be one in which the seedlings are distributed in a purely random manner. This was used by Clarke (1972), Grant (1951) and others. However, it is generally accepted that natural regeneration follows a strongly clustered rather than a random distribution in most situations (Wellner 1940, Gill 1950, and others). Payandeh (1974) found that even trees in mature stands are generally clustered.

Construction of the Test Populations: The use of computer-generated seedling populations represents a compromise between the field approach and the mathematical approach. Because of the wide range of seedling density and distribution encountered in natural regeneration areas, it was not possible to model every situation. It was decided to restrict the study to conditions that appeared to be typical of areas that are marginal between success and failure - strongly clustered with stocking levels in the $40 \%$ to $60 \%$ range. Four such populations were generated with the properties shown in Table 1 , each representing seedlings on a 10-ha area, $400 \mathrm{~m}$ by $250 \mathrm{~m}$. All calculations were done on a UNIVAC 1108 computer.

For the two-large-clustered populations, the generation procedure followed was to first determine, from mean density and mean cluster width, the number of circular clusters required and the mean number $\mathrm{ms}$ of seedlings per cluster. Cluster centres were then generated at random ${ }^{2}$ throughout the area, and the number of seedlings per cluster selected at random from 1 to $2 \mathrm{~ms}$. The seedlings were then generated about each centre so that the distribution of the distance from the centre to the seedlings was exponential. The degree of clustering was controlled by the value of the constant in the exponential distribution. Finally, a limit was imposed on the seedling distance to make each cluster area proportional to its number of seedlings.

To make the populations more realistic, certain clusters were removed, and replaced elsewhere,

Table 1. Properties of the generated populations

\begin{tabular}{|c|c|c|c|c|}
\hline \multicolumn{2}{|c|}{ Mean density } & $\begin{array}{c}\text { Mean } \\
\text { cluster } \\
\text { width }\end{array}$ & $\begin{array}{c}\text { Variance- } \\
\text { to-mean } \\
\text { ratio* }\end{array}$ & $\begin{array}{l}\text { Per cent } \\
\text { stocking }\end{array}$ \\
\hline $\begin{array}{l}2500 \\
2500 \\
5000 \\
5000\end{array}$ & $\begin{array}{l}1000 \\
1000 \\
2000 \\
2000\end{array}$ & $\begin{array}{r}30 \mathrm{~m} \\
5 \mathrm{~m} \\
30 \mathrm{~m} \\
5 \mathrm{~m}\end{array}$ & $\begin{array}{l}3.3 \\
2.3 \\
4.8 \\
3.4\end{array}$ & $\begin{array}{l}43 \\
46 \\
58 \\
60\end{array}$ \\
\hline
\end{tabular}

* Ratio increases with degree of clustering. Random populations have a ratio of 1 .

${ }^{1}$ This paper deals only with sampling error caused by an uneven seedling distribution. This component of the total error (the other part is caused by mistakes of the field crew) contains no bias, so that both the term "accuracy" or "precision" could be employed. to produce patches without seedlings. These cover about $15 \%$ of the area and represent swamps, rock outcrops or other features. An approximate computer plot is shown in Figure 1.

For the two small-clustered populations, the procedure was similar with one additional feature. The population was given a directional trend, such as may be found where topography was formed by glaciation, by generating elliptical seedling clusters with a length/width ratio of 2.5 instead of circular clusters. The long axes of the clusters were given a tendency to be oriented in a particular direction. Part of one population is shown in Figure 2.

Sampling Procedure: A systematic design was employed for all stocking surveys of the generated populations, with plots or quadrats $2 \mathrm{~m} \times 2 \mathrm{~m}^{3}$ in size. Surveys employing groups of adjacent plots were carried out as well as single-plot surveys

(Figure 3), since grouped-plot surveys are in common use in Canada.

The plots or plot groups were set out along parallel equidistant sample lines (Figure 4) and were evenly spaced along these lines. The spacing varied from $20 \mathrm{~m}$ by $62.5 \mathrm{~m}^{4}(\mathrm{x}=20 \mathrm{~m}, \mathrm{~d}=62.5$ $\mathrm{m}$ in Figure 4) to $80 \mathrm{~m}$ by $250 \mathrm{~m}$.

For each combination of population, spacing and group type 100 surveys were run, with the initial line spacing $d_{1}$ and plot or group spacings $x_{1}, X_{2}$, etc. selected at random for each survey. A standard error was estimated from the usual formula:

$$
\mathrm{SE}=\left[\sum_{\mathrm{i}=1}^{\mathrm{n}}\left(\mathrm{y}_{\mathrm{i}}-\mathrm{m}\right)^{2} /(\mathrm{n}-1)\right]^{1 / 2}
$$

where $n$ is 100 in this case, $y_{1}$ to $y_{n}$ are the per cent stocking values and $m$ is the mean to the $y_{1}$.

Extension of Results to Large Regeneration Areas: The 10-ha area $(250 \mathrm{~m} \times 400 \mathrm{~m})$ modelled by the generated seedling populations was considered the minimum for which results could safely be applied to larger areas. If a large regeneration area is divided into $\mathrm{n} 10$-ha sections, the standard error $S_{n}$ for a stocking survey over the whole area can be derived from:

$$
\mathrm{S}_{\mathrm{n}}=\frac{\mathrm{S}}{\sqrt{\mathrm{n}}} \ldots \ldots \ldots \ldots \ldots \ldots \ldots \ldots \ldots \ldots \ldots
$$

where $\mathrm{S}$ is the error over each section.

This formula requires the assumptions that the stocking levels on each section are independent of each other, and that the standard error over each section is the same. If sections were too small, features such as a rock outcrop or swamp might extend over several adjacent sections. The
2The UNIVAC subroutine RANDM was used for all random number generations.

3Plot area is .00099 acres or approximately 1 milacre.

11 chain $=20 \mathrm{~m}$ approximately. 


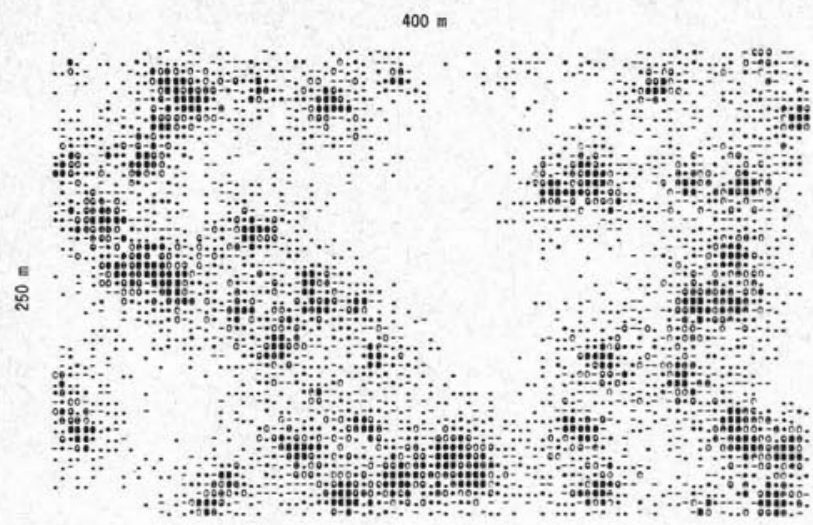

Figure 1. Large-clustered population, 2500 seedlings/ha (computer plot - shading indicates local density).

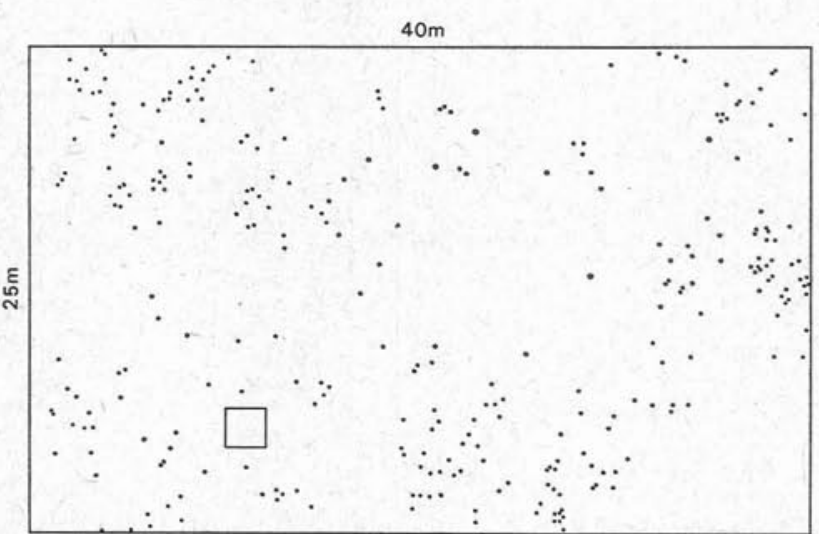

Figure 2. Part of small-clustered population, 5000 seedlings/ ha (only $1 \%$ of sample area is shown. The square is a $2 \mathrm{~m} \times 2 \mathrm{~m}$ plot).

relatively poorly stocked sections would then tend to occur adjacent to one another, violating the independence assumption.

\section{Results and Discussion}

Comparisons among Seedling Populations: In spite of the different properties of the four test populations, the standard errors (Table 2) were generally close for any given plot or group spacing. These variations in standard error were significant ${ }^{5}$ at the $95 \%$ level for none of the singleplot spacings, 1 of the group-of-4, and 3 of the group-of-10. For the purpose of this survey, which is to provide approximate guidelines for regeneration survey design, it appeared that mean values (Table 2) could be used to derive the relationship of standard error to sampling intensity (number of plots per area).

There was a difference, however, in the sensitivity of the populations to the way the plots were distributed for any fixed sampling intensity. The standard errors were generally larger for surveys where plots were concentrated on fewer sample lines than if the plots were evenly spaced, and also larger for plots concentrated in plot groups than for single plots. These effects were greater

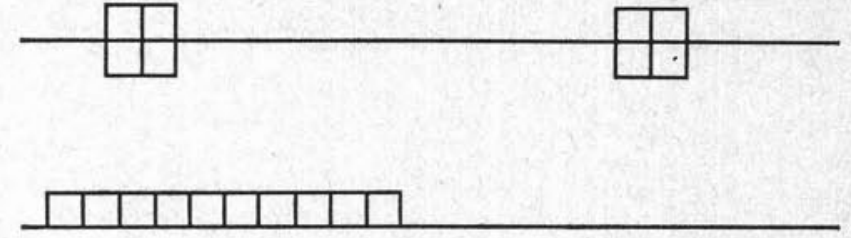

Figure 3. Plot groups tested.

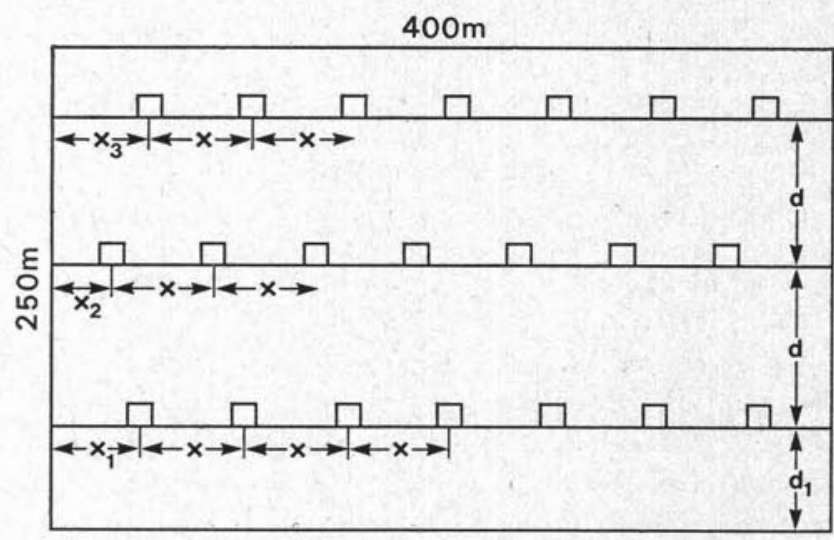

Figure 4. Systematic survey design employed.

for the two large-clustered populations than for the small-clustered. The reason appears to be that with large seedling clusters, stocking levels change more gradually along any sample line so that a plot set out close to other plots provides relatively less additional information. Because of this difference, analyses of the effect of plot distribution (independent of intensity) were done separately for the two population types.

Relationship of Standard Error to Sampling Intensity: The mean standard errors for each spacing were plotted in Figure 5 . The curves were fitted manually rather than by regression because of the small number of data points. To avoid the plot distribution effects mentioned, at each intensity only the errors for the relatively evenly spaced surveys were used (e.g. at 8 plots/ha, the $20 \mathrm{~m} \times 62.5 \mathrm{~m}$ results were used, not the $10 \mathrm{~m} \mathrm{x}$ $125 \mathrm{~m}$ results).

For comparison purposes, the theoretical relationship between standard error and intensity, averaged over four random seedling populations with the same stocking levels as the generated populations, was plotted using the formula:

$$
\mathrm{SE}=[\mathrm{p}(1-\mathrm{p}) / \mathrm{n}) \frac{1}{2}
$$

where $p$ is the stocking level and $n$ is the number of plots.

Example - Suppose that stocking is to be determined over an area of 100 ha (250 acres) with a

5Bartlett's test for homogeneity of variance. (See Snedcor \& Cochrane p. 296). 
standard error of $2.5 \%$. Substituting 10 for $\mathrm{n}$ and $2.5 \%$ for $S_{n}$ in formula (1) gives

$$
2.5 \%=\mathrm{S} / \sqrt{10}
$$

Thus S, the equivalent standard error over one 10 ha section, is $7.9 \%$. From Figure 5 , using the curves midway between the curves for large and small-clustered populations, we find that an error of $7.9 \%$ requires 3.0 evenly spaced single plots per ha, 5.6 plots/ha in groups of 4 or 8.7 plots/ha in groups of 10 . This suggests the following approximate spacings, to the nearest $10 \mathrm{~m}$ :

$50 \mathrm{~m} \times 60 \mathrm{~m}$ (2.5 chains $\times 3$ chains) for single plots,

$75 \mathrm{~m} \times 100 \mathrm{~m}$ ( 3.75 chains $\times 5$ chains) for groups of 4 plots,

or $100 \mathrm{~m} \times 120 \mathrm{~m}$ ( 5 chains $\times 6$ chains) for groups of 10 plots.

Grouped-Plot vs Single-Plot Surveys: From Figure 5, grouped-plot surveys are less efficient than single plot surveys on a per plot basis. This implies that a group of adjacent plots provides less stocking information than the same number of evenly spaced plots. On the other hand, a group of plots provide more information than one single plot.

A contributing factor to the total sampling time required by a survey is the number of times a sampling crew must stop along a sample line to put in plots. Surveys employing evenly spaced plots necessitate a stop for each plot, while grouped-plot surveys require only one stop per group. Figure 6 shows that while the number of plots required by group-plot surveys is larger than for evenly spaced surveys to achieve the same

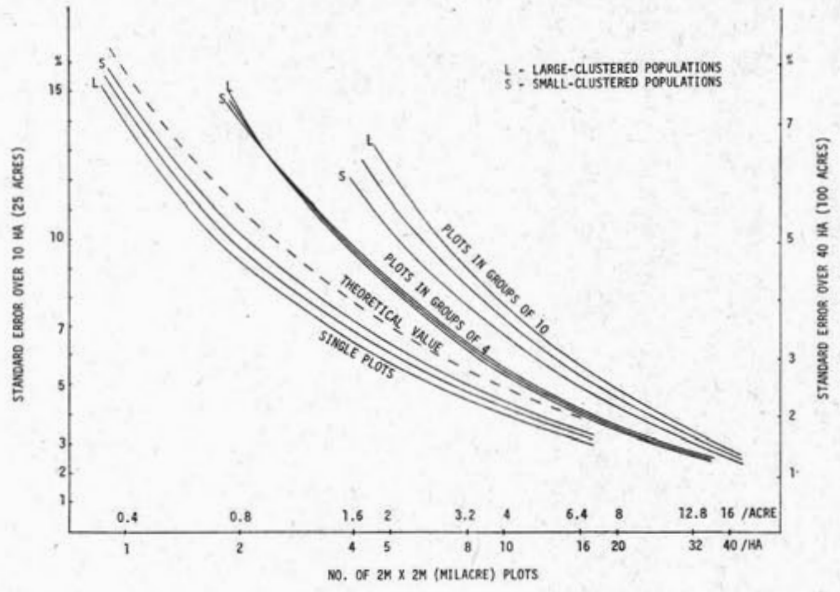

Figure 5. Standard error vs sampling intensity for evenly spaced plots.

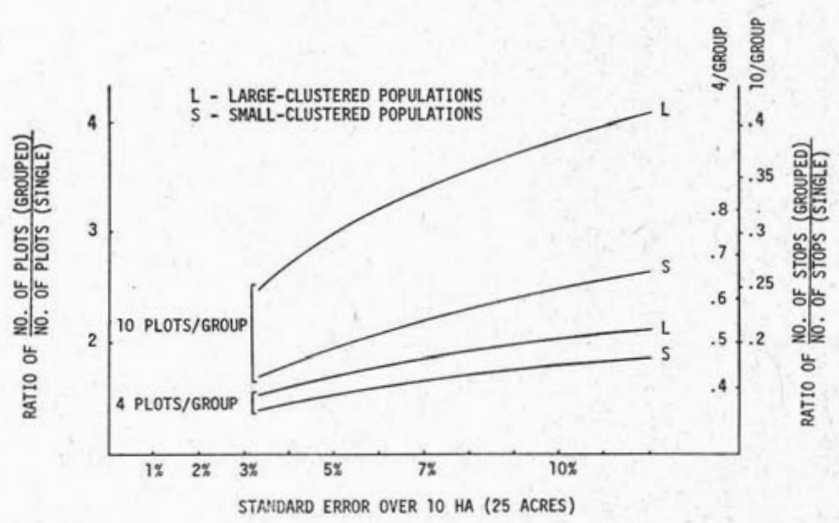

Figure 6. Relative sampling intensities for single plots and plot groups.

Table 2. Standard errors for per cent stocking (each value calculated from 100 surveys over a 10 -ha area)

\begin{tabular}{|c|c|c|c|c|c|c|}
\hline \multirow[b]{2}{*}{ Plot or Group spacing } & \multirow[b]{2}{*}{$\begin{array}{l}\text { Plots per } \\
\text { ha (acre) }\end{array}$} & \multicolumn{4}{|c|}{$\begin{array}{l}\text { Seedling populations } \\
\text { Small }\end{array}$} & \multirow[b]{2}{*}{$\underset{\text { SE }}{\text { Mean* }}$} \\
\hline & & $\begin{array}{c}\text { Larg } \\
2500 / \text { ha }\end{array}$ & $\begin{array}{l}\text { clusters } \\
5000 / \text { ha }\end{array}$ & $\begin{array}{c}\text { Small } \\
2500 / \mathrm{ha}\end{array}$ & $\begin{array}{l}\text { lusters } \\
5000 / \text { ha }\end{array}$ & \\
\hline 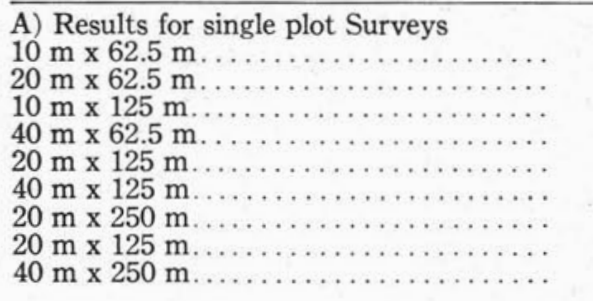 & $\begin{array}{l}16(6.4) \\
8(3.2) \\
8(3.2) \\
4(1.6) \\
4(1.6) \\
2(\quad .8) \\
2(\quad .8) \\
1(\quad .4) \\
1(\quad .4)\end{array}$ & $\begin{array}{l}3.49 \% \\
4.13 \\
6.48 \\
6.69 \\
7.51 \\
9.57 \\
11.76 \\
15.13 \\
14.70\end{array}$ & $\begin{array}{l}2.99 \% \\
4.51 \\
5.42 \\
6.90 \\
6.66 \\
8.47 \\
11.30 \\
13.16 \\
14.04\end{array}$ & $\begin{array}{l}3.78 \% \\
5.00 \\
5.47 \\
6.47 \\
7.56 \\
10.57 \\
10.62 \\
15.53 \\
13.92\end{array}$ & $\begin{array}{l}3.40 \% \\
4.81 \\
5.54 \\
7.31 \\
6.98 \\
9.86 \\
11.18 \\
15.18 \\
14.31\end{array}$ & $\begin{array}{l}3.43 \% \\
4.62 \\
5.74 \\
6.85 \\
7.19 \\
9.65 \\
11.22 \\
14.78 \\
14.25\end{array}$ \\
\hline 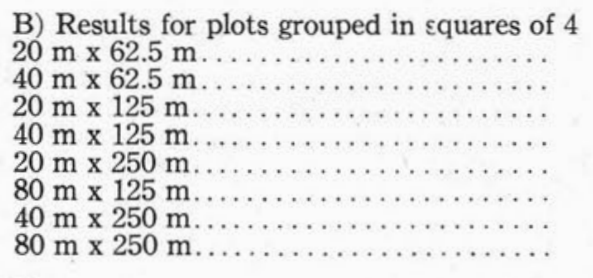 & $\begin{array}{r}32(12.8) \\
16(6.4) \\
16(6.4) \\
8(3,2) \\
8(3.2) \\
4(1.6) \\
4(1.6) \\
2(r .8)\end{array}$ & $\begin{array}{r}2.98 \\
4.02 \\
5.51 \\
6.37 \\
8.69 \\
9.60 \\
10.07 \\
14.39\end{array}$ & $\begin{array}{r}2.74 \\
3.91 \\
5.01 \\
5.88 \\
8.83 \\
9.04 \\
10.43 \\
14.84\end{array}$ & $\begin{array}{r}2.96 \\
4.28 \\
4.86 \\
6.72 \\
6.83 \\
9.66 \\
9.02 \\
13.90\end{array}$ & $\begin{array}{r}3.04 \\
4.12 \\
5.04 \\
6.22 \\
7.84 \\
10.14 \\
9.25 \\
13.42\end{array}$ & $\begin{array}{r}2.93 \\
4.08 \\
5.11 \\
6.30 \\
8.09 \\
9.62 \\
9.71 \\
14.15\end{array}$ \\
\hline 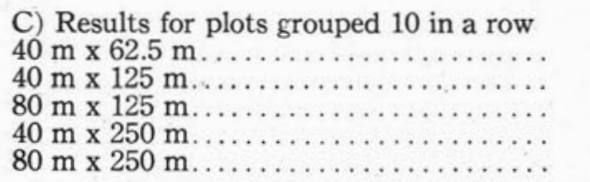 & $\begin{array}{c}40(16) \\
20(8) \\
10(4) \\
10(4) \\
5(2)\end{array}$ & $\begin{array}{r}2.75 \\
5.06 \\
8.05 \\
8.45 \\
12.50\end{array}$ & $\begin{array}{r}2.35 \\
4.58 \\
7.42 \\
8.40 \\
12.11\end{array}$ & $\begin{array}{l}2.58 \\
3.67 \\
5.76 \\
6.70 \\
9.20\end{array}$ & $\begin{array}{r}2.96 \\
4.59 \\
7.50 \\
6.91 \\
10.82\end{array}$ & $\begin{array}{r}2.67 \\
4.50 \\
7.23 \\
7.66 \\
11.23\end{array}$ \\
\hline
\end{tabular}

-The root mean square was taken rather than the ordinary mean. 
level of accuracy, the number of stops required is smaller. Figure 6 is based directly on the curves in Figure 5.

The increase in number of plots required is proportionately greater over the large-clustered popu-

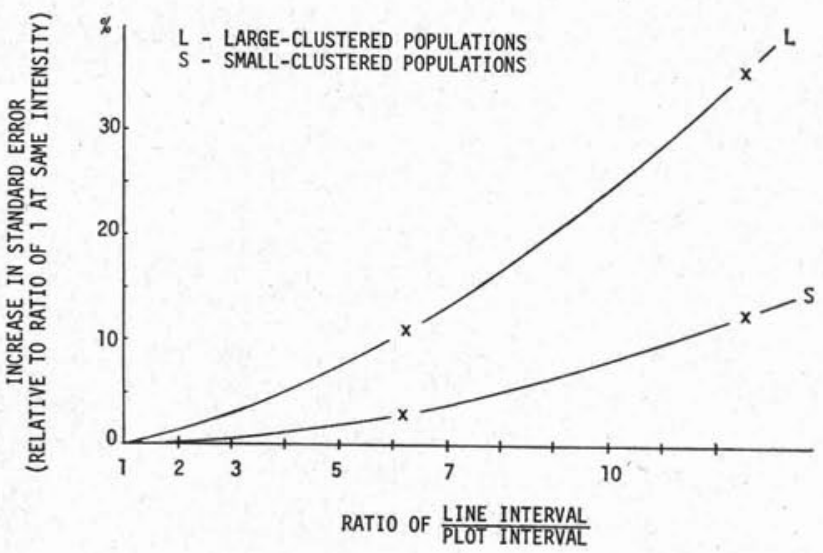

Figure 7. Dependence of standard error on line interval/ plot interval ratio.

lations, and the reduction in number of stops is less. These effects are also seen to depend on the level of accuracy.

From Figure 6, for example, the curve for 10 plots per group for a small-clustered population indicates a ratio of about 2 on the left vertical axis for a standard error of $5 \%$ on the horizontal axis. This indicates that to maintain a standard error of $5 \%$, in switching from single plots to plots in groups of 10 , requires a doubling of the number of sample plots. The number of stops required, however, read on the right vertical axis, is only 0.2 times as many as for the single-plot survey.

Effect of the Ratio of Plot Interval to Line Interval: Any given sampling intensity can be achieved from a variety of different combinations of plot and line spacing, each with a different line inter$\mathrm{val} / \mathrm{plot}$ interval ratio (d/ $\mathrm{x}$ in Figure 3). In Table 2, several cases exist of two different ratios for the same intensity (e.g. $20 \mathrm{~m} \times 62.5 \mathrm{~m}$ and $10 \mathrm{~m} \times 125$ $\mathrm{m})$. From the standard errors for these cases, an approximate relationship between ratio and standard error was plotted in Figure 7, to show the ratio effect for any given sampling intensity. The curves were fitted manually to the data points indicated.

For example, with large clustered populations, an increase in the line interval/plot interval ratio from 1 to 10 produces a relative increase of about $25 \%$ in the standard error - e.g. from $4 \%$ to $5 \%$, or $8 \%$ to $10 \%$ etc. These relationships appear to hold for both grouped-plot and single plot surveys, for all the sampling intensities used.

\section{Conclusion}

This study indicates that only a moderate number of sample plots are necessary to achieve a reasonable level of stocking accuracy, provided that there is no additional error because of mis- takes or bias of the sampling crew. For example, an intensity of 2 mil-acre plots per ha $(0.8$ per acre), if evenly spaced, would produce a standard error of $10 \%$ over 10 ha (25 acres) or $5 \%$ over 40 ha (100 acres).

The number of sample lines can be reduced considerably by using designs with relatively high ratios of line interval to plot interval. This is particularly true if the seedlings tend to occur in small clusters rather than large ones. Even in the latter case, for example, a ratio of 5 to 1 would require in general about $20 \%$ more plots in total, but only about half the number of sample lines, as an evenly spaced survey for the same accuracy.

The use of groups of plots instead of single plots will also reduce the number of sample lines, particularly for small-clustered populations. For an average population and a standard error of about $5 \%$ over 40 ha (100 acres), substitution of groups of 4 plots instead of single plots would increase the total number of plots by about $100 \%$ but reduce the number of sampling stops by $50 \%$, and the number of lines by about $30 \%$. Substitution of groups of 10 increases the number of plots required by up to $200 \%$, but reduces the number of stops by $70 \%$ and the number of lines by $45 \%$.

It should be noted again that the above results are most relevant to seedling populations with densities and degrees of clustering within the range of the generated populations. For extremely clustered populations, the expected standard errors would be greater than the results given here. For fairly evenly spaced populations, or for populations with stocking outside the marginal range - e.g. over $75 \%$ or under $25 \%$ - the standard errors would be somewhat less.

\section{References}

Clarke, F. R. 1972. A comparison of sampling designs for regeneration cruising. Ontario Ministry of Natural Resources.

Cottam, G., J. T. Curtis and B. W. Hale. 1975. Some sampling characteristics of a population of randomly dispersed individuals. Ecology 34: 741-757.

Ghent, A. W. 1963. Studies of regeneration in forest stands devastated by spruce budworm. III Problems of sampling precision and seedling distribution. For. Sci. 9(3): 295-310.

Gill, C. B. 1950. A study of the relationship between numbers of trees per acre and dispersion. For Chron. 26: 186-196.

Grant, J. A. C. 1951. The relationship between stocking and size of quadrat. University of Toronto Forestry Bulletin.

Payandeh, B. 1974. Spatial patterns of trees in the major forest types of northern Ontario. Can. J. For. Res. 4: 8-14.

Persson, O. 1973. On forestry regeneration surveys. In Statistics in Forestry Research, IUFRO 4th Conf. Advis. Group For. Stat., Vancouver, August 1973. p. 17-35.

Pielou, E. C. 1957. The effect of quadrat size on the estimation of the parameters of Neyman's and Thomas' distributions. J. Ecol. 45: 31-47.

Pielou, E. C. 1959. The use of point to plant distances in the study of the patterns of plant populations. J. Ecol. 47: 607613.

Snedecor, G. W. and W. G. Cochran. 1971. Statistical Methods (6th ed.). lowa State University Press.

Wellner, C. A. 1940. Relationships between three measures of stocking in natural reproduction of the western white pine type. J. For. 38: 636-638. 


\section{THE CANADIAN INSTITUTE OF FORESTRY}

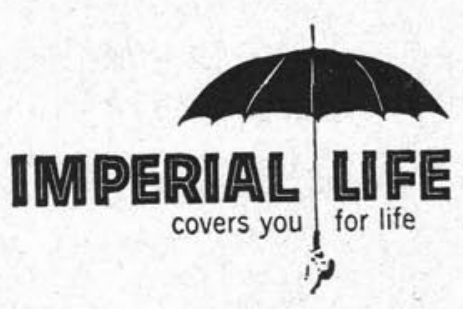

We've been together for 17 years providing life insurance protection for CIF members and today that protection is better than ever...

- We've increased the maximum amount of coverage available from $\$ 40,000^{\circ}$ to $\$ 100,000$ (up to age 50 ).

- We've kept the same low premium rates.

- We've extended eligible enrollment to include members' spouses and full-time employees of members of the Institute.

- We're paying a $50 \%$ bonus on any claims arising during the period May 1 , 1977 to April 30, 1978. This is the second consecutive year that the bonus has been $50 \%$, it was previously $25 \%$. It means that if, for example, you arrange $\$ 100,000$ of protection, $\$ 150,000$ would be payable at no extra cost during this 12 -month period.

For more information about how you can take full advantage of this valuable life insurance plan the CIF has arranged for you, write to The Canadian Institute of Forestry, Box 5000, Macdonald College, P.Q. HOA 1 CO.

\section{Kbm FORESTRY CONSULTANTS INC.}

115 N. CUMBERLAND STREET THUNDER BAY, ONTARIO P7A $4 \mathrm{M} 3$ TEL.: 344-0811

RESOURCE INVENTORY FOREST MANAGEMENT PLANNING

SILVICULTURAL SPECIALISTS SYSTEM DESIGN AND CONTRACT

\section{EDWARD FELLOWS}

FORESTRY \& FOREST PRODUCTS CONSULTANT

P.O. Box 354, 404 Queen St., FREDERICTON, N. B.

Registered Professional Forester (N. B.)
MEMBER:

Canadian Institute of Forestry Forest Products Research Society, Etc. INDUSTRY DEVELOPMENT - FOREST PRODUCTS ECONOMIC FOREST POLICY \& ADMINISTRATION

320 Maple Street,

Fredericton, N.B.

GORDON B. YOUNG, B.Sc.F., M.F

Registered Professional Forester$$
\text { Fredericton, N.B. }
$$

Bus.: 506 - 472-3396

Home: 506 - 472-7721 